\title{
Observation of risk factors, clinical manifestations and genetic characterization of recent Newcastle Disease Virus outbreak in West Malaysia
}

\author{
Seetha Jaganathan ${ }^{1,3,4}$, Peck Toung Ooi ${ }^{*}$, Lai Yee Phang ${ }^{2}$, Zeenathul Nazariah Binti Allaudin ${ }^{1}$, Lai Siong Yip ${ }^{5}$,
} Pow Yoon Choo ${ }^{5}$, Ban Keong Lim ${ }^{5}$, Stephane Lemiere ${ }^{6}$ and Jean-Christophe Audonnet ${ }^{6}$

\begin{abstract}
Background: Newcastle disease virus remains a constant threat in commercial poultry farms despite intensive vaccination programs. Outbreaks attributed to ND can escalate and spread across farms and states contributing to major economic loss in poultry farms.

Results: Phylogenetic analysis in our study showed that eleven of the samples belonged to genotype VIId. All farms were concurrently positive with two immunosuppressive viruses; Infectious Bursal Disease Virus (IBDV) and Marek's Disease Virus (MDV). Amino acid sequence analysis confirmed that eleven of the samples had sequence motifs for velogenic/mesogenic strains; three were lentogenic.

Conclusion: In conclusion, no new NDV genotype was isolated from the 2011 NDV outbreak. This study suggests that the presence of other immunosuppressive agents such as IBD and MDV could have contributed to the dysfunction of the immune system of the chickens, causing severe NDV outbreaks in 2011. Risk factors related to biosecurity and farm practices appear to have a significant role in the severity of the disease observed in affected farms.
\end{abstract}

Keywords: Newcastle disease virus, Infectious Bursal Disease, Marek's Disease, Immunosuppressive agents, Recent outbreak, Risk factors, Phylogenetic study, Genetic characterization

\section{Background}

Newcastle disease (ND) is a highly contagious viral disease in domestic poultry, aviary and wild birds. Despite intensive vaccination programs, the virus remains a constant threat to the commercial poultry farms in Malaysia [1]. The disease is classified in the World Organization for Animal Health (OIE) as a notifiable disease (formerly list A) [2, 3]. It is a member of the order Mononegavirales, family Paramyxoviridae and genus Avulavirus with an enveloped virus which has a negative-sense, non-segmented singlestranded RNA genome consisting of 15,586 nucleotides [4]. Its genome comprises six genes: nucleoprotein $(\mathrm{NP})$, phosphoprotein $(\mathrm{P})$, matrix protein $(\mathrm{M})$, fusion glycoprotein (F), hemagglutinin-neuraminidase (HN) glycoprotein and large polymerase protein (L). Of the 6

\footnotetext{
* Correspondence: ooi@upm.edu.my

${ }^{1}$ Department of Clinical Studies, Faculty of Veterinary Medicine, Universiti

Putra Malaysia, 43400 UPM, Serdang, Selangor, Malaysia

Full list of author information is available at the end of the article
}

genes found in NDV, its two membrane proteins, the F gene and the HN gene are most important in determination of its virulence. The fusion $(\mathrm{F})$ protein is responsible in mediating fusion of the viral envelope with cellular membranes and the haemagglutinin-neuraminidase $(\mathrm{HN})$ protein is involved in cell attachment and release [4-6].

Newcastle disease virus strains are classified into 3 pathotypes, highly virulent (velogenic), intermediate (mesogenic) or non-virulent (lentogenic) [7]. Traditionally, NDV pathotypes are most commonly distinguished by nucleotide sequencing. The consensus sequence of the $\mathrm{F}$ protein cleavage site of velogenic and mesogenic strains is ${ }^{112}(\mathrm{R} / \mathrm{K}) \mathrm{RQ}(\mathrm{R} / \mathrm{K}) \mathrm{RF}^{117}$; the consensus sequence of the lentogenic $F$ cleavage site is ${ }^{112}(\mathrm{G} / \mathrm{E})(\mathrm{K} / \mathrm{R}) \mathrm{Q}(\mathrm{G} / \mathrm{E}) \mathrm{RL}^{117}$ $[7,8]$. A recent finding documented that a change of glutamine to basic residue arginine $(\mathrm{R})$ at position 114 of the F cleavage site reduced the viral replication and attenuated the virus pathogenicity. The paper also 
reported that the pathogenicity was further reduced when isoleucine (I) at position 118 was substituted by valine [9].

NDV isolates have been classified into lineages or genotypes based on the analysis of the fusion (F) gene. Aldous et al. 2003 initially used the lineage classification system which grouped NDV isolates into six lineages (1-7) and 13 sub-lineages. Another lineage (lineage 7) and seven other sub-lineages were later proposed. Another classification for NDV classifies the virus into two major groups called class I and class II. There are nine genotypes (1-9) in Class I and eleven genotypes (I-XI) in Class II (2) with genotypes I, II, VI, and VII being further divided into sub-genotypes $1 \mathrm{a}$ and $1 \mathrm{~b}$, II and IIa, VIa through VIf and VIIa through VIIh [10-13]. Genotype I consists of the avirulent strains of NDV, while viruses of genotypes II, III and IV were reported to be responsible for the first panzootics before the 1960s [10]. Genotype $\mathrm{V}$ was thought to be responsible for the second panzootics in the early 1970s and genotype VII viruses caused the third panzootics in racing pigeons during the 1980s $[4,6,8,14-21]$. Severe outbreaks in Western Europe, South Africa and Southern Europe, Taiwan and China since the early 1990s have been caused by the prevalent genotype VII (VIIa-VIId), constituting the fourth panzootic of NDV [14-16, 18, 22]. Genotype VIII has been found to cause enzootic infections in Southern Africa and is believed to have originated from the Far East [15]. Genotype IX of the ND virus has caused sporadic NDV infections in some regions of China [2, 19], whereas Tsai et al. first demonstrated novel genotype $\mathrm{X}$ viruses in Taiwan [18, 21, 23, 24].

The clinical signs and pathological lesions of ND vary with the age and species of birds, the immune status of the host and environmental conditions. A very high number of NDV cases with high mortality in broilers and lower prevalence in layers, breeders and native broilers were reported by field veterinarians towards the end of 2010 through 2011 in Malaysia. Newcastle disease virus infection was suggested as the tentative diagnosis on the basis of history, clinical syndrome, gross lesions, serology as well as isolation of NDV, or the presence of NDV by PCR and/or molecular characterization of the fusion protein gene. These cases were reported in farms which had various combinations of primary and booster vaccinations with lentogenic as well as mesogenic NDV vaccine, or inactivated NDV vaccines. Though vaccinated with NDV vaccines, some of the chicken farms were totally wiped out. Various hypotheses were raised to explain the occurrences of the disease which included 1 ) a change in pathogenicity of ND virus, 2) vaccine and vaccination practices, and 3) concurrent infection with other immunosuppression organisms or presence of other non-infectious agents. Previous studies have demonstrated the presence of genotype VII and genotype II in Malaysia from 2004 until 2010 [1, 20, 25]. Here we will describe the genetic characterization of the recent isolates from the 2011 NDV outbreaks in West Malaysia with the objective of assessing the risk factors associated with the disease in affected farms. This will investigate the presence of IBDV and MDV as possible immunosuppressive agent, and to determine if there are any new NDV genotype in the 2011 outbreak cases.

\section{Methods}

\section{Animals ethics}

All samples were collected under the supervision of institution veterinarians. The study was conducted following the guidelines as stated in the Code of Practice for Care and use of Animals for Scientific Purposes as stipulated by Universiti Putra Malaysia and complied with the current guidelines for the care and use of animals and was approved by the Institutional Animal Care and Use Committee (IACUC), Faculty of Veterinary Medicine, Universiti Putra Malaysia. There was no experimental research done on the animals. No animals were deliberately sacrificed or injured during the sampling procedure. Every effort was made to minimize any distress or unnecessary culling.

\section{Sampling}

Organ samples were collected from twelve broiler farms displaying typical clinical signs for ND (Fig. 1) in various states in West Malaysia. Five sick birds per farm were sacrificed for the collection of specimens (trachea, lung, spleen, caecal tonsils, proventriculus, intestine, brain, liver, kidney, lymph nodes, bone marrow and bursal of Fabricius). Two farms from East Malaysia with no clinical ND infection were included into the study as negative control.

Consent was obtained from all farm owners for the harvesting of chicken organ samples from their farms.

\section{Observation of risk factors and clinical manifestation}

A standardized survey was used to assess risk factors associated with the high mortality observed. The survey covered the following parameters 1) flock characteristics, 2) vaccination programs, 3) mortality and morbidity rates, 4) age of occurrence, clinical and necropsy lesions and 5) farm management factors such as single/ multi age farming practices, source of day old chick (DOC), breed of broilers, number of houses affected, stocking density, disease in neighboring farm, previous history of poor performance/mortality, measures taken in outbreak, measures taken after outbreak for next cycle and performance of the next 2 grow-outs after 


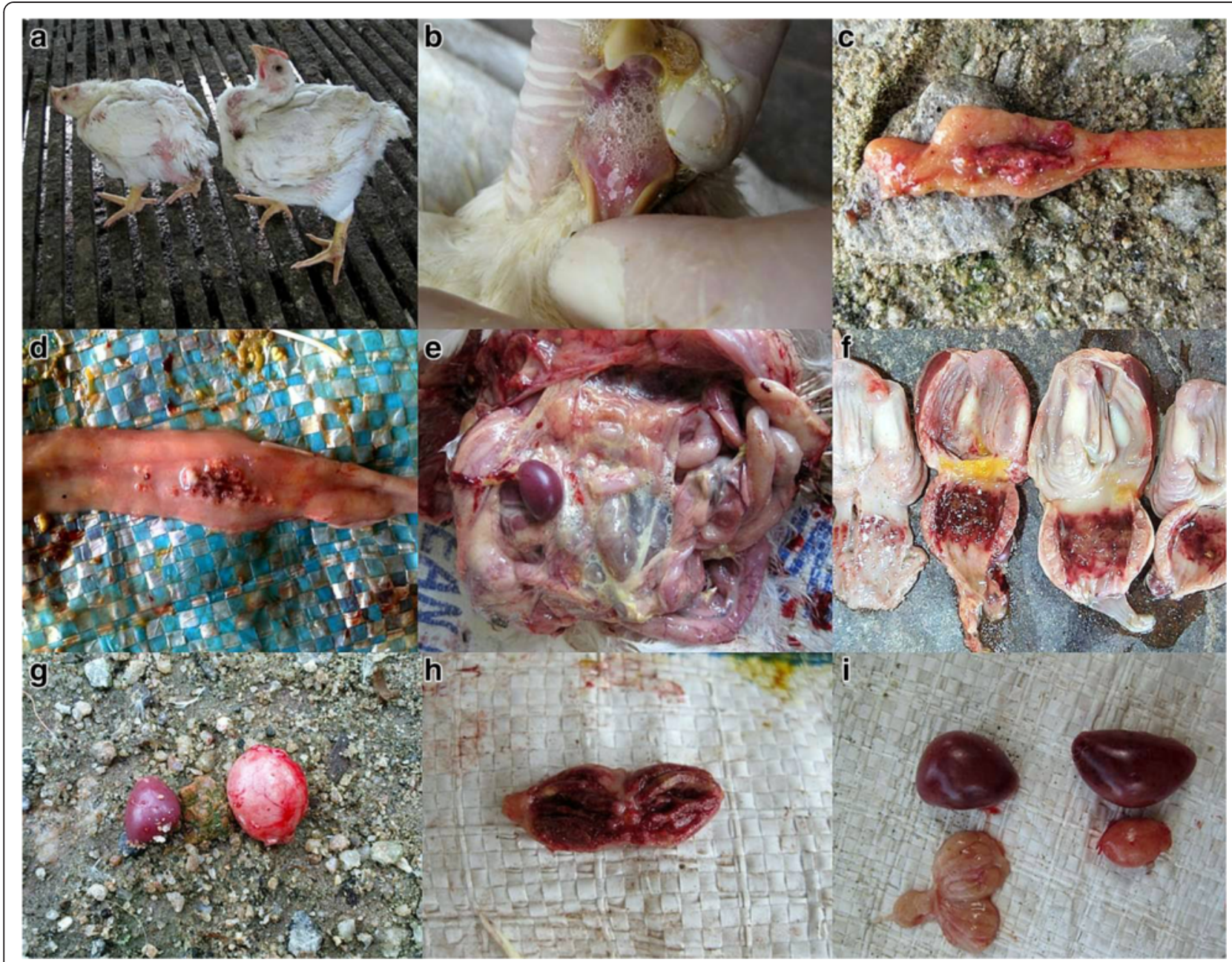

Fig. 1 Clinical signs observed from the outbreak. a A typical torticollis is shown. These symptoms normally occur 7 to 10 days after a complaint of high mortality is reported. $\mathbf{b}$ In severely affected birds, mild swollen head and dyspnea with profuse secretions in the trachea were found. $\mathbf{c} \& \mathbf{d}$ Hemorrhagic \& necrosis of intestines especially the caecal tonsils \& peyer's patches were found. e Upon PM, the trachea was severely congested and late in the disease stages pericarditis, perihepatitis and caseous air sacculitis were observed. f Proventicular hemorrhages were consistent. $\mathbf{g}$, $\mathbf{h} \& \mathbf{i}$ Bursa atrophy was also commonly found in the outbreak. The cut surfaces of the bursa were hemorrhagic - quite atypical from ND infection which prompted us to look for other infectious agents. Not shown above was atrophic thymus

first incidence. A scoring system (1-5) with 1 (poor) to 5 (very good) was used to evaluate the biosecurity and disinfection status of farms. The data was compiled and analyzed using $t$-test, chi $(\mathrm{X})^{2}$ and appropriate statistical tests to compare with the negative controls.

\section{Serology}

Serum samples were collected from only four farms from vaccinated flocks (25-40 days), as the study was conducted from commercial production farms with current ND outbreaks. It was not possible to obtain paired serum samples for comparison from every farm as the severity of the outbreak caused very high mortality. The ND-HI titer analysis was conducted by Vet Food Agro Diagnostics (M) Sdn. Bhd.

\section{Screening of NDV, IBD, MDV}

Organ samples were pooled for screening by real-time PCR for NDV and for other immunosuppressive agents i.e., MDV and IBDV. The organ samples were subjected to nucleic acid extraction by using the Trizol LS reagent (Invitrogen, USA) following the standard manufacturer's protocol. The real time PCR was established from methods previously described [1, 26, 27]. The real time PCR mixtures consisted of $10 \mu \mathrm{l}$ of SYBR green master mix, the respective primer sets and PCR grade water to make up the final volume of $20 \mu \mathrm{l}$ per reaction. The PCR mixtures were subjected to real time PCR amplification in a 384-well microplate in the LC480 Real Time PCR instrument (LC 480, Roche). The melting peaks and melting curves were observed 
by using the Absolute Quant Software provided with the instrument. The respective primer sets are as follow, NDV primers specific for the fusion protein gene, 5 '-ATG GGC(C/T) CCA GA(C/T) CTT CTA C-3' (forward) and 5' -CTG CCA CTG CTA GTT GTG ATA ATC C-3' (reverse) (Amplicon size: $545 \mathrm{bp}$ ); IBD primers, 5'-GT RAC RAT CAC ACT GTT CTC AGC-3' (Y=C/T); $(\mathrm{R}=\mathrm{A} / \mathrm{G})$ (forward) and $5^{\prime}$-GAT GTR AYT GGC TGG GTT ATC TC-3' (reverse) (Amplicon size: 248 bp); MDV-serotype 1 primers, 5'-GAC TCG CTC GCA CAT C-3' (forward) and 3'-CGA CAC TCC GCA GTT-5' (reverse) (Amplicon size: $102 \mathrm{bp}$ ); MDV-serotype 2 primers; 5'-GTT TCG TCT ACC ACC CG-3' (forward) and 5'ATG CCA CTG TAT TTG ATC TCC-3' (reverse) (Amplicon size: $139 \mathrm{bp}$ ); MDV-serotype 3 primers, 5'ACC GCA ACT CTT CTC ACA-3' (forward) and 3'CTC GGG CAA CCT CTA CAT-5' (reverse) (Amplicon size: $201 \mathrm{bp}$ ). Primer sets for MDV serotype 1, 2 and 3 were designed by using the Primer Premier 5 software from Premier Biosoft.

\section{Sequencing, amino acid sequence analysis, phylogenetic construction of NDV from the 2011 outbreak}

The same primer sets for amplifying NDV as described above $[1,26]$ were used for sequencing. The PCR products of the expected amplicon sizes were purified by using the PCR clean-up gel extraction kit according to the manufacturer's protocol with slight modifications (Analytik Jena, Germany). Sequencing of the fusion protein gene of NDV from the 14 farms was done in a commercial sequencing facility using the BigDye ${ }^{\circ}$ Terminator v3.1 cycle sequencing kit. In order to confirm that all positive cases were true Newcastle disease virus, a Basic Local Alignment Search Tool (BLAST) search of the sequence was done in the Genbank ${ }^{\circ}$ database (Data not shown). The sequence editing and assembly were done by using BioEdit ${ }^{\circ}$ Sequence Alignment Editor version 7.0.5.2 (Tom Hall, US). Sequences were aligned by using Clustal $\mathrm{X}^{\mathrm{x}}$. The phylogenetic tree was constructed by using the distancebased neighbor joining method by using Mega $^{\text {Tim }} 5$ software (Biodesign Institute, Tempe, Arizona) and evaluated using the bootstrapping method calculated on 1000 repeats of the alignment. The sequence identity matrix was generated with BioEdit ${ }^{\circ}$ Sequence Alignment Editor version 7.0.5.2 (Tom Hall, US). All sequences used for constructing the phylogenetic tree are listed in Table 1.

\section{Results \& discussion}

\section{Observation of risk factors and clinical manifestations}

The results of the survey are shown in Tables 2, 3, 4 and 5. Table 2 describes farm characteristics and type of breeds used. All farms were multi-age broiler farms stocked with various commercial breeds namely Cobb, Ross or commercial native birds. The mean flock population was about 90,000 broilers $(83.3 \%$ of houses were open sided houses). On average, 7.2 houses were affected. Over $90 \%$ of the farms surveyed were located within $1 \mathrm{~km}$ radius to other broiler and reported high mortality in neighboring farms. More than $50 \%$ of the farms had poor performance in its two previous grow-outs $(P<0.05)$, reported that the day-old-chick quality were poor in the affected flock $(P<0.01)$ and had unsubstantiated evidence that the chicks were sourced from breeder flocks which had been reported with high mortalities resembling ND $(P<0.05)$. The average age of onset of disease was $15.9(P<0.05)$ days old which was reported to be at the time or after IBD vaccinations were administered and 28 days in the negative control farms.

The frequency of vaccination in the 12 study farms for Newcastle disease, Infectious Bronchitis, Infectious Bursal disease, Marek's disease and Swollen Head Syndrome (SHS); a disease caused by Avian metapneumovirus; were $100 \%, 100 \%, 91.7 \%, 8.3 \%$ and $8.3 \%$ respectively (Table 4 ). The frequency of ND vaccination for lentogenic, mesogenic and inactivated vaccines were $100 \%, 33.3 \%$ and $50.0 \%$ with all farms practicing multiple ND vaccinations in the lifecycle of the broilers. Biosecurity and farm sanitation scores were 1.7 and 2.6 respectively.

The onset of clinical 'ND' disease was reported at 15.9 days old $(P<0.05)$ with a final grow out mortality of affected flocks at $32.3 \%(P<0.05)$ (Table 5). All the farms initiated treatment with antimicrobials and supportive treatments (vitamins and electrolyte) and upgraded sanitation and disinfection practices when the disease was observed or when advised by field veterinarians. The primary clinical signs were inappetance, depression, ruffled feathers, whitish to greenish and watery diarrheoa, head swelling and dyspnoea. Torticollis was seen at about 7-10 days after the onset of clinical signs. Gross pathology lesions included profuse fluids in the trachea and bronchus, congested trachea, gizzard and proventricular erosions and hemorrhages, hemorrhages on Peyer's patches and caecal tonsils and in other visceral organs. Bursa $(P<$ 0.05 ) and thymus atrophy were present in the majority of cases. The disease process appeared to be of acute onset with significantly reduced observations of air sacculitis, perihepatitis and peritonitis $(P<0.05)$. NDV, IBDV and MDV were detected in organs and tissues at $100 \%, 83 \%$ and $83 \%$ respectively by PCR, with MD Serotypes 2, 1 and 3 in descending order of detection. NDV, IBDV and MDV were detected concurrently in $75 \%$ of farms (Table 6). The concurrent presence of IBDV and MDV with NDV were significant at $P<0.05$ and with the presence of MDV Serotype $1(P<0.01)$. 
Table 1 NDV isolates derived from this study and other isolates reported previously

\begin{tabular}{|c|c|c|c|c|c|}
\hline No & Isolate name & $\begin{array}{l}\text { Genbank }^{\circledast} \\
\text { accession } \\
\text { number }\end{array}$ & Genotype & Country & Reference \\
\hline 1 & $\begin{array}{l}\text { V4 } \\
\text { Queensland }\end{array}$ & M24693 & I & Australia & Genbank $^{\otimes}$ \\
\hline 2 & Ulster/67 & M24694 & । & N. Ireland & Genbank $^{\circledast}$ \\
\hline 3 & F7 & JN613118 & । & Malaysia & This study \\
\hline 4 & Lasota & M24696 & $\|$ & USA & Genbank $^{\circledast}$ \\
\hline 5 & MB061/07 & GQ901891 & $\|$ & Malaysia & Genbank $^{\circledast}$ \\
\hline 6 & F5 & JN613116 & $\|$ & Malaysia & Genbank $^{\circledast}$ \\
\hline 7 & F6 & JN613117 & $\|$ & Malaysia & $G^{-}$bank ${ }^{\circledast}$ \\
\hline 8 & Miyadera & M24701 & III & Japan & Genbank $^{\circledast}$ \\
\hline 9 & Italien & EU293914 & IV & Italy & Genbank $^{\circledast}$ \\
\hline 10 & Herts/33 & AY741404 & IV & UK & Genbank $^{\circledast}$ \\
\hline 11 & CA1085/71 & AF001106 & V & USA & Genbank $^{\circledast}$ \\
\hline 12 & $\mathrm{H}-10 / 72$ & AF001107 & V & Hungary & Genbank $^{\circledast}$ \\
\hline 13 & TX3503/04 & EU477190 & $\mathrm{VI}$ & USA & Genbank $^{\circledast}$ \\
\hline 14 & NDV05-027 & DQ439885 & $\mathrm{VI}$ & China & Genbank $^{\circledast}$ \\
\hline 15 & Q-GB 506/97 & AF109887 & $\mathrm{VI}$ & UK & Genbank $^{\circledast}$ \\
\hline 16 & DK-1/95 & AF001129 & $\mathrm{Vl}$ & Denmark & Genbank $^{\circledast}$ \\
\hline 17 & Iraq AG68 & AF001108 & VI & Iraq & Genbank $^{\circledast}$ \\
\hline 18 & Lebanon-70 & AF001110 & $\mathrm{VI}$ & Lebanon & Genbank $^{\circledast}$ \\
\hline 19 & MB047/05 & GQ901895 & Vlla & Malaysia & Genbank $^{\circledast}$ \\
\hline 20 & $\begin{array}{l}\text { Cockatoo/ } \\
14698 / 90\end{array}$ & AY288998 & Vlla & Indonesia & Genbank $^{\circledast}$ \\
\hline 21 & ZA360/95 & AF109876 & VIllb & S. Africa & Genbank $^{\oplus}$ \\
\hline 22 & ZW3422/95 & AF109877 & VIllb & Zimbabwe & Genbank $^{\circledast}$ \\
\hline 23 & NDV05-055 & DQ439910 & VIlc & China & Genbank $^{\oplus}$ \\
\hline 24 & TW/2000 & AF358786 & $\mathrm{VIll} / \mathrm{d}$ & Taiwan & Genbank $^{\circledast}$ \\
\hline 25 & F8 & JN613119 & VIld & Malaysia & Genbank $^{\oplus}$ \\
\hline 26 & $\mathrm{Ch} / 2000$ & AF358788 & Vlld & China & Genbank $^{\oplus}$ \\
\hline 27 & MB064/05 & GQ901893 & VIId & Malaysia & Genbank $^{\oplus}$ \\
\hline 28 & MB016/07 & GQ901894 & VIld & Malaysia & Genbank $^{\circledast}$ \\
\hline 29 & $\mathrm{~F} 1$ & JN613112 & VIId & Malaysia & This study \\
\hline 30 & F2 & JN613113 & VIld & Malaysia & This study \\
\hline 31 & F3 & JN613114 & VIld & Malaysia & This study \\
\hline 32 & F4 & JN613115 & VIld & Malaysia & This study \\
\hline 33 & F9 & JN613120 & VIId & Malaysia & This study \\
\hline 34 & F10 & JN613121 & VIId & Malaysia & This study \\
\hline 35 & F11 & JN613122 & VIld & Malaysia & This study \\
\hline 36 & $\mathrm{~F} 12$ & JN613123 & VIId & Malaysia & This study \\
\hline 37 & F13 & JN613124 & VIld & Malaysia & This study \\
\hline 38 & F14 & JN613125 & VIld & Malaysia & This study \\
\hline 39 & MB043/06 & GQ901896 & Vlld & Malaysia & Genbank $^{\oplus}$ \\
\hline 40 & MB091/05 & FJ008916 & VIId & Malaysia & Genbank $^{\oplus}$ \\
\hline 41 & MB093/05 & FJ008917 & VIld & Malaysia & Genbank $^{\circledast}$ \\
\hline
\end{tabular}

Table 1 NDV isolates derived from this study and other isolates reported previously (Continued)

\begin{tabular}{|c|c|c|c|c|c|}
\hline 42 & MB095/05 & FJ008918 & VIId & Malaysia & Genbank $^{\circledast}$ \\
\hline 43 & MB128/04 & FJ008923 & VIld & Malaysia & Genbank $^{\circledast}$ \\
\hline 44 & DE143/95 & AF109881 & VIld & UK & Genbank ${ }^{\circledast}$ \\
\hline 45 & TW/95-1 & AF083960 & Vlle & Taiwan & Genbank $^{\circledast}$ \\
\hline 46 & MB076/05 & GQ901892 & Vlle & Malaysia & $G^{-}$bank ${ }^{\circledast}$ \\
\hline 47 & AF2240 & AF048763 & VIII & Malaysia & Genbank ${ }^{\circledast}$ \\
\hline 48 & MB085/05 & GQ901901 & VIII & Malaysia & Genbank \\
\hline 49 & $\mathrm{QH}-1 / 79$ & AF378250 & VIII & China & Genbank $^{\circledast}$ \\
\hline 50 & $\mathrm{QH}-4 / 85$ & AF378252 & VIII & Malaysia & Genbank $^{\oplus}$ \\
\hline 51 & ZhJ-1/85 & AF458023 & IX & Malaysia & Genbank ${ }^{\circledast}$ \\
\hline 52 & FJ-1/85 & AF458009 & IX & Malaysia & Genbank $^{\circledR}$ \\
\hline
\end{tabular}

\section{Serology}

Serology results from one farm (Farm 6) showed that the antibody titer was low and not as expected with a mean titer of 1.8. Antibody titer from three other farms (Farm 4, 7 and 8) was very high for a broiler which indicates that there's an infection.

\section{Screening for NDV, IBD and MDV}

Samples from all farms were found to be positive for NDV, IBD and MDV, and clearly evident that immunosupression continues to be a major problem for the poultry industry. IBDV is one of the most common immunosuppressive agents in poultry. It primarily targets the bursa of Fabricious which is committed to the differentiation and proliferation of B-lymphocytes into antibody-producing plasma cells. In the bursa, IBDV produces severe destruction of B-lymphocytes by either necrosis or apoptosis, and consequently the antibody-mediated response (humoral) is affected [27, 28]. Recent studies have also demonstrated that this virus can also hinder some of the mechanisms of cellular immunity making chickens more susceptible to viral respiratory infections and elevating mortality. Thus, the immune response to vaccines is impaired and the overall productive performance may be significantly decreased in all types of chickens. Similarly, Marek's Disease, which is an ubiquitous, complex, lymphoproliferative disease of chickens caused by a strong cell-associated alpha herpesvirus, MD virus (MDV) is

Table 2 Comparison of serology titer from the surveyed ND outbreak vs. serology titer from non-survey farms ND outbreak

\begin{tabular}{llll}
\hline & & GMT & Mean \\
\hline Farm 6 (survey) & ND outbreak with IBD and & 1.5 & 1.8 \\
& MD detected & & \\
Farm 4, 7, 8 (survey) & ND outbreak with IBD and & 212.8 & 390.4 \\
& MD detected & & \\
\hline
\end{tabular}


Table 3 Farm characteristics and history

\begin{tabular}{lll}
\hline Risk factor & $\begin{array}{l}\text { Affected } \\
\text { farms }\end{array}$ & $\begin{array}{l}\text { Negative } \\
\text { controls }\end{array}$ \\
\hline No of farms & 12 & 2 \\
Number of broilers per farm & $89,950^{\mathrm{a}}$ & $87,500^{\mathrm{a}}$ \\
Number of houses per farm & $11.1^{\mathrm{a}}$ & $6.5^{\mathrm{a}}$ \\
Number of houses affected per farm & $7.2^{\mathrm{a}}$ & $1.5^{\mathrm{a}}$ \\
Type of management - multi-age & Multi-age & Multi-age \\
Type of housing - open-sided housing & Open & Open \\
Farms within 1 km of affected farm & $92 \%^{\mathrm{a}}$ & $50 \%^{\mathrm{a}}$ \\
Poor performance in the last 2 grow outs & $50 \%^{\mathrm{c}}$ & $0 \%{ }^{\mathrm{d}}$ \\
Neighboring farms with history of disease & $91.7 \%^{\mathrm{a}}$ & $0 \%^{\mathrm{b}}$ \\
Complaints of poor day-old-chick quality & $50 \%^{\mathrm{c}}$ & $50 \%^{\mathrm{d}}$ \\
Disease after IBD vaccination or about Week 2-3 & $83.3 \%^{\mathrm{a}}$ & $50 \%^{\mathrm{b}}$ \\
Suspected source of chicks from breeder farms & $66.7 \%^{\mathrm{a}}$ & $0 \%^{\mathrm{b}}$ \\
\hline with disease & & \\
\hline
\end{tabular}

Note: ${ }^{a, b}$ Values in different columns bearing different superscripts are significantly different $(P<0.05)$, ${ }^{c, d}$ Values in different columns bearing different superscripts are significantly different $(P<0.01)$

progressive in nature with a relatively long incubation period and the virulent virus can remain in the host without producing any clinical syndromes [23, 24, 29, 30]. The primary cell targets of MDV infection are lymphocytes, and as a result, early effects are mainly seen in lymphoid organs such as the bursa of Fabricius (source of B lymphocytes), the thymus (primary source of $\mathrm{T}$ lymphocytes) and the spleen. Consequences of these MDVinduced immunosuppresion have also shown to cause reduced resistance to other concurrent infections [29-31]. Therefore, based on the findings, the presence of IBD and MDV suggest a significant negative impact on the immune system and growth of these broiler chickens. NDV itself was not immunosuppressive, and vaccination with killed-NDV vaccines failed to reduce incidences of NDV outbreaks, because the core underlying factors such as IBD and MDV that were causing sub-clinical infections were not addressed, thus reducing the protective effect of the NDV vaccination programs.

Table 4 Vaccination and assessment of biosecurity and sanitation status

\begin{tabular}{lll}
\hline Risk factor & Affected farms & Negative controls \\
\hline Biosecurity status & $1.7^{\mathrm{a}}$ & $2.5^{\mathrm{a}}$ \\
Sanitation and disinfection status & $2.6^{\mathrm{a}}$ & $2.5^{\mathrm{a}}$ \\
Vaccination with NDv & $100 \%{ }^{\mathrm{a}}$ & $100 \%{ }^{\mathrm{a}}$ \\
Vaccination with IBV & $100 \%{ }^{\mathrm{a}}$ & $100 \%{ }^{\mathrm{a}}$ \\
Vaccination with IBDV & $91.7 \%^{\mathrm{a}}$ & $91.7 \%^{\mathrm{a}}$ \\
Vaccination with MDV & $8.3 \%{ }^{\mathrm{a}}$ & $0 \%{ }^{\mathrm{b}}$ \\
Vaccination with SHSv & $8.3 \%{ }^{\mathrm{a}}$ & $0 \%{ }^{\mathrm{b}}$ \\
\hline
\end{tabular}

Note: ${ }^{a, b}$ Values in different columns bearing different superscripts are significantly different $(P<0.05)$, ${ }^{c, d}$ Values in different columns bearing different superscripts are significantly different $(P<0.01)$
Table 5 Zootechnical results, clinical and necropsy findings

\begin{tabular}{lll}
\hline Risk factor & $\begin{array}{c}\text { Affected } \\
\text { farms }\end{array}$ & $\begin{array}{l}\text { Negative } \\
\text { controls }\end{array}$ \\
\hline Age of first occurrence of disease & $15.9^{\mathrm{a}}$ & $28.0^{\mathrm{a}}$ \\
Age of clinical and necropsy examination & $24.8^{\mathrm{a}}$ & $32.5^{\mathrm{a}}$ \\
Mortality at grow-out, \% & $32.3 \%^{\mathrm{a}}$ & $4.5 \%^{\mathrm{b}}$ \\
Presence of respiratory disease & $100 \%^{\mathrm{a}}$ & $100 \%^{\mathrm{a}}$ \\
Presence of enteric disease & $100 \%^{\mathrm{a}}$ & $0 \%^{\mathrm{b}}$ \\
Torticolis and neurological signs & $91.7 \%^{\mathrm{a}}$ & $0 \%^{\mathrm{b}}$ \\
Haemorrhages in more than 1 visceral organ & $83.3 \%^{\mathrm{a}}$ & $0 \%{ }^{\mathrm{b}}$ \\
Thymus atrophy & $100 \%^{\mathrm{a}}$ & $0 \%{ }^{\mathrm{b}}$ \\
Bursal atrophy & $75 \%^{\mathrm{a}}$ & $50 \%{ }^{\mathrm{b}}$ \\
Ascites & $8.3 \%^{\mathrm{a}}$ & $50 \%^{\mathrm{a}}$ \\
Air-sacculitis, perihepatitis and peritonitis & $16.7 \%^{\mathrm{a}}$ & $50 \%{ }^{\mathrm{b}}$ \\
Clouded air sacs & $50 \%^{\mathrm{c}}$ & $100 \%{ }^{\mathrm{d}}$ \\
\hline Note: a,bValues in different columns bearing different superscripts are \\
$\begin{array}{l}\text { significantly different }(P<0.05), \mathrm{c}, \mathrm{d} \text { Values in different columns bearing different } \\
\text { superscripts are significantly different }(P<0.01)\end{array}$
\end{tabular}

\section{Sequencing, amino acid sequence analysis, phylogenetic construction}

BLAST $^{\circ}$ analysis showed that all samples were true NDV cases when compared with other sequences on Genbank ${ }^{\circ}$. Amino acid sequence analysis of the $535 \mathrm{bp}$ fragment of the fusion protein $(\mathrm{F})$ gene of the fourteen Malaysian NDV isolates showed that eleven of the isolates were categorized as velogenic virus and three were lentogenic. The eleven velogenic strain had the F cleavage site motif ${ }^{112} \mathrm{R}-\mathrm{R}-\mathrm{R}-\mathrm{K}-\mathrm{R}-\mathrm{F}^{117}$ while two of the lentogenic strain had the F cleavage site motif ${ }^{112} \mathrm{G}-\mathrm{R}-\mathrm{Q}-\mathrm{G}-\mathrm{R}-\mathrm{L}^{117}$, whilst one sequence had the $\mathrm{F}$ cleavage site motif ${ }^{112} \mathrm{G}-\mathrm{K}-\mathrm{Q}-\mathrm{G}-$ $\mathrm{R}-\mathrm{L}^{117}$ at the $\mathrm{C}$-terminus of the $\mathrm{F} 2$ protein and phenylalanine (F) residue at amino acid position 117 of the $\mathrm{N}$ terminus of the F1 protein (Table 7). Phylogenetic analysis revealed that 11 of the Malaysian isolates clustered closely with the genotype VIId strains, one of the Malaysian isolate grouped together with genotype I and two of the isolates grouped with genotype II (Fig. 2). Of the eleven Malaysian isolates that grouped to form genotype VIId, ten (F1, F2, F3, F4, F9, F10, F11, F12, F13, F14) had

Table 6 Detection of infectious agents concurrently with NDV positive samples

\begin{tabular}{ll}
\hline $\begin{array}{l}\text { Presence of concurrent infectious agent in } \\
\text { disease farms }\end{array}$ & Frequency of detection \\
\hline IBD & $83.0 \%$ \\
MD & $83.0 \%$ \\
IBD+MD & $75.0 \%$ \\
MD Serotype 1 & $58.0 \%$ \\
MD Serotype 2 & $75.0 \%$ \\
MD Serotype 3 & $67.0 \%$ \\
\hline
\end{tabular}


Table 7 The F cleavage site and it's pathotypes from the Malaysian isolates

\begin{tabular}{|c|c|c|c|c|c|}
\hline Isolate & Genbank $^{\oplus}$ accession no & F cleavage site & Genotype & Pathotype & Source \\
\hline $\mathrm{F} 1$ & JN613112 & RRRKRF & VIId & Velogenic/Mesogenic & This study \\
\hline F2 & JN613113 & RRRKRF & VIld & Velogenic/Mesogenic & This study \\
\hline F3 & JN613114 & RRRKRF & VIld & Velogenic/Mesogenic & This study \\
\hline $\mathrm{F} 4$ & JN613115 & RRRKRF & VIId & Velogenic/Mesogenic & This study \\
\hline F5 & JN613116 & GRQGRL & $\|$ & Lentogenic & This study \\
\hline F6 & JN613117 & GRQGRL & $\|$ & Lentogenic & This study \\
\hline F7 & JN613118 & GKQGRL & । & Lentogenic & This study \\
\hline F8 & JN613119 & RRRKRF & VIId & Velogenic/Mesogenic & This study \\
\hline F9 & JN613120 & RRRKRF & VIld & Velogenic/Mesogenic & This study \\
\hline F10 & JN613121 & RRRKRF & VIld & Velogenic/Mesogenic & This study \\
\hline F11 & JN613122 & RRRKRF & VIld & Velogenic/Mesogenic & This study \\
\hline $\mathrm{F} 12$ & JN613123 & RRRKRF & VIId & Velogenic/Mesogenic & This study \\
\hline F13 & JN613124 & RRRKRF & VIld & Velogenic/Mesogenic & This study \\
\hline F14 & JN613125 & RRRKRF & VIId & Velogenic/Mesogenic & This study \\
\hline
\end{tabular}

between 97.9 to $98.7 \%$ sequence identity similarities with other Malaysian isolates responsible for the Newcastle disease outbreaks in 2004-2005 and 2007 which were previously reported by researchers from Universiti Putra Malaysia [20, 28, 31]. All these isolates have between 91 and $92 \%$ similarities with the Indonesian strain (cockatoo/14698/90). One (F8) of the Malaysian isolate which grouped with genotype VIId had $96.1 \%$ similarities with the China strain (Ch/2000). Of the three lentogenic strains isolated from this study, two (F5, F6) had between 97.4 and $97.5 \%$ nucleotide sequence similarities with genotype II while one isolate (F7) had around $88.8 \%$ nucleotide sequence similarities with genotype I.

Overall, based on the amino acid sequence analysis, eleven of the farms displayed the typical sequence motifs for velogenic/mesogenic, while three had the sequence motif for lentogenic strains. This correlates with the fact that two of the samples (F6 \& F7) were collected as negative controls from farms with no mortality. Based on phylogenetic investigations, eleven (F1, F2, F3, F4, F8, F9, F10, F11, F12, F13, F14) of the samples clustered with the genotype VIId and had a very close relationship with the previously isolated Malaysian isolates (MB043/06, MB091/06, MB093/05, MB095/05, MB128/04) which suggest that similar NDV strains have been circulating in this region for several years now [1, 20, 25].

\section{Nucleotide sequence accession numbers}

The complete genomic sequences of the 14 NDV isolates reported in this paper were deposited with the GenBank $^{\oplus}$ database under accession numbers JN613112,
JN613113, JN613114, JN613115, JN613116, JN613117, JN613118, JN613119, JN613120, JN613121, JN613122, JN613123, JN613124 and JN613125.

These sequences are downloadable from Entrez ${ }^{\mathrm{rm}}$ Pop Set data as a group of sequences.

\section{Conclusion}

The present study confirms that similar velogenic NDV genotype VIId, as reported previously, were detected in the study farms in spite of vaccination. In addition, no new genotype of ND virus was found based on the genetic characterization. IBDV and MDV were also concurrently detected by PCR. Immunosuppressive agents play a significant role in vaccination failures. However, the role, interactions and effect of these immunosuppressive agents as well as other concurrent infectious and non infectious agents not studied in the disease process could not be fully ascertained. Risk factors such as multi-age production practices, close proximity of farms, biosecurity and sanitation practices appear to have a role in the outcome of the disease, in terms of severity, mortality, clinical and pathological findings. Preventive measures taken post outbreak such as improved biosecurity and sanitation appear to have mediated improved performance in subsequent grow-outs. The findings from this study suggest that there may not be a need for a new vaccine as the same genotype that has been present for a long time is still responsible for the current ND outbreaks. Further to that, the findings also suggest that risk factors related to biosecurity and farm practices appear to have a significant role in the severity of the disease observed 


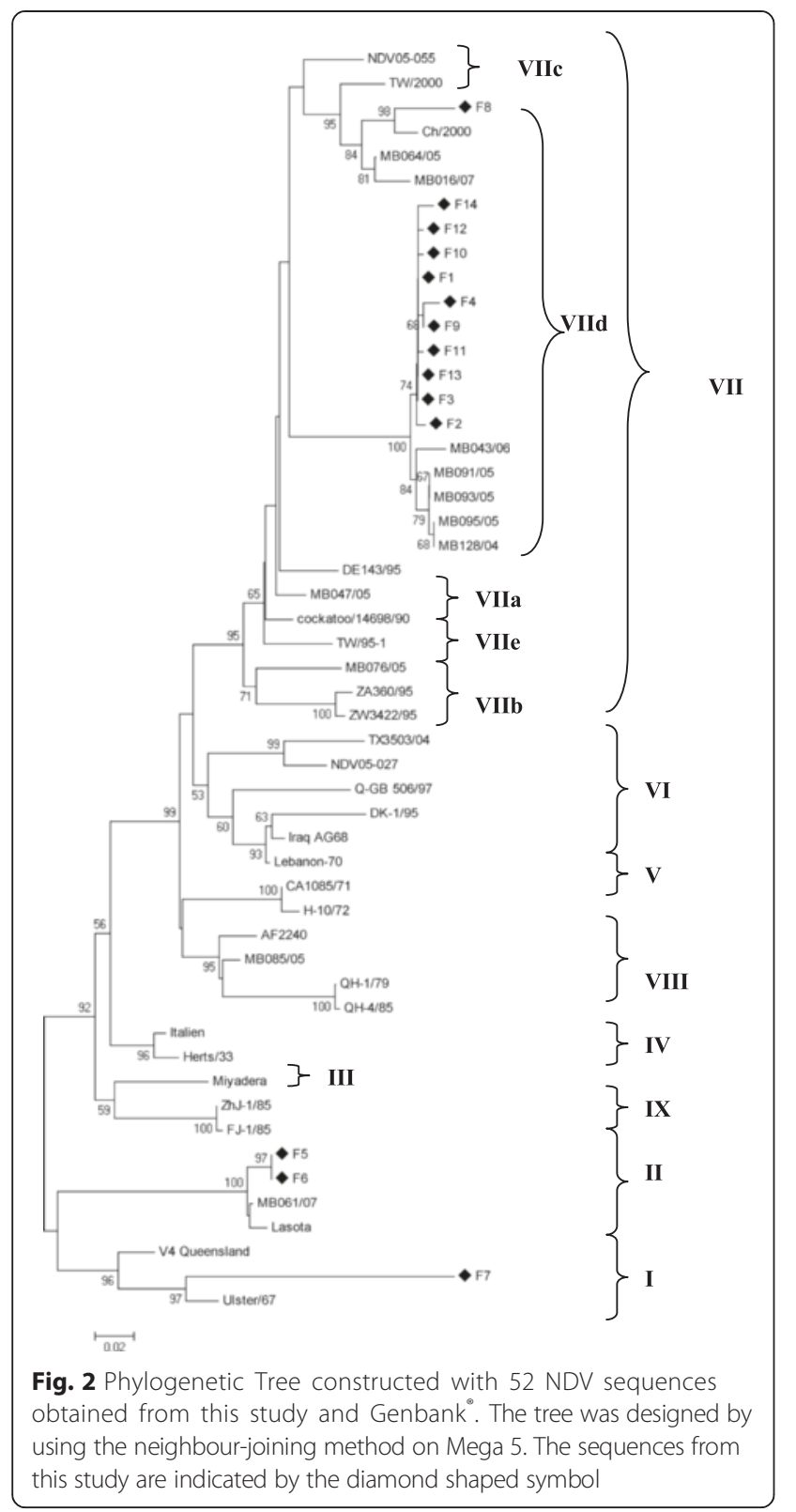

in affected farms. If those factors are alleviated, the severity of the ND problems in farms would be greatly reduced.

\section{Abbreviations}

NDV: Newcastle disease virus; IBDV: Infectious bursal disease virus; MDV: Marek's disease virus; PCR: polymerase chain reaction; MDV: Marek's Disease Virus; SHS: Swollen Head Syndrome.

\section{Competing interests}

The authors declare that they have no competing interests.

\section{Authors' contributions}

SJ participated in the conceptual aspect of the work, conceived the research, performed the experiments and wrote the manuscript. OPT, PLY, ZNA, YLS, CPY, LBK, SL, JCA provided consultation and coordination. All authors read and approved the final manuscript.

\section{Acknowledgements}

The authors would like to thank Vet Food Agro Diagnostics (M) Sdn. Bhd for providing the samples for this study and Rhone Ma Malaysia Sdn. Bhd. and Merial for funding the research.

\section{Disclaimer}

This document is provided for scientific purposes only. Any reference to a brand or trademark herein is for informational purposes only and is not intended for a commercial purpose or to dilute the rights of the respective owner(s) of the brand(s) or trademark(s).

\section{Author details}

${ }^{1}$ Department of Clinical Studies, Faculty of Veterinary Medicine, Universiti Putra Malaysia, 43400 UPM, Serdang, Selangor, Malaysia. ${ }^{2}$ Department of Biotechnology, Faculty of Biotechnology \& Molecular Science, Universiti Putra Malaysia, 43400, UPM, Serdang, Selangor, Malaysia. ${ }^{3}$ Asia-Pacific Special Nutrients Sdn. Bhd, Lot 18B, Jalan 241, Section 51A, 46100 Petaling Jaya, Selangor, Malaysia. ${ }^{4}$ Vet Food Agro Diagnostic Sdn. Bhd., Lot 18B, Jalan 241, Section 51A, 46100 Petaling Jaya, Selangor, Malaysia. ${ }^{5}$ Rhone Ma Malaysia (M) Sdn Bhd, Lot 18B, Jalan 241, Section 51A, 46100 Petaling Jaya, Selangor, Malaysia. ${ }^{6}$ Merial S.A.S., Bio R\&D, 254, Rue Marcel Merieux, 69007 Lyon, France.

Received: 6 March 2015 Accepted: 6 August 2015

Published online: 21 August 2015

\section{References}

1. Berhanu A, Aini I, Omar AR, Bejo MH. Molecular characterization of partial fusion gene and $\mathrm{C}$-terminus extension length of haemagglutinin-neuraminidase gene of recently isolated Newcastle disease virus isolates in Malaysia. Virol J. 2010;7:183.

2. Liu XF, Wan HQ, Ni XX, Wu YT, Liu WB. Pathotypical and genotypical characterization of strains of Newcastle disease virus isolated from outbreaks in chicken and goose flocks in some regions of China during 1985-2001. Arch Virol. 2003;148:1387-403.

3. Lomniczi B, Wehmann E, Herczeg J, Ballagi-Pordany A, Kaleta EF, Werner O, et al. Newcastle disease outbreaks in recent years in Western Europe were caused by an old (VI) and a novel genotype (VII). Arch Virol. 1998;143:49-64.

4. Phillips RJ, Samson ACR, Emmerson PT. Nucleotide sequence of the 5'-terminus of Newcastle disease virus and assembly of the complete genomic sequence: agreement with the 'rule of six'. Arch Virol. 1998;143:1993-2002.

5. Mayo MA. Virus taxonomy - Houston 2002. Arch Virol. 2002;147:1071-6.

6. Millar NS, Emmerson PT. Molecular cloning and nucleotide sequencing of Newcastle disease virus, chapter 5. In: Alexander DJ, editor. Newcastle disease. Boston: Kluwer; 1988. p. 79-97.

7. Aldous EW, Alexander DJ. Technical review: detection and differentiation of Newcastle disease virus (avian paramyxovirus type 1). Avian Pathol. 2001;30:117-28.

8. Alexander DJ. Newcastle disease. In: Purchase HG, Arp LH, Domermuth CH, Pearson JE, editors. A laboratory manual for the isolation and identification of avian pathogens. 3rd ed. Kennett Square: American Association of Avian Pathologist; 1989. p. 114-20.

9. Samal S, Kumar S, Khattar SK, Samal SK. A single amino acid change Q114R in cleavage site sequence of Newcastle Disease Virus fusion protein attenuates viral replication and pathogenicity. J Gen Virol. 2011;92(Pt 10):2333-8.

10. Diel DG, Silva LHA, Liu H, Wang Z, Miller PJ, Afonso CL. Genetic diversity of avian paramyxovirus type 1: Proposal for a unified nomenclature and classification system of Newcastle disease virus genotypes. Infection, Gen Evol. 2012;12:1770-9.

11. Aldous EW, Mynn JK, Banks J, Alexander DJ. A molecular epidemiological study of avian paramyxovirus type 1 (Newcastle disease virus) isolates by phylogenetic analysis of a partial nucleotide sequence of the fusion protein gene. Avian Pathol. 2003;32(3):239-56.

12. Perozo F, Merino R, Afonso CL, Villegas P, Calderon N. Biological and phylogenetic characterization of virulent Newcastle disease virus circulating inMexico. Avian Dis. 2008:52(3):472-9.

13. Perozo F, Marcano R, Afonso CL. Biological and Phylogenetic Characterization of a Genotype VII Newcastle Disease Virus from Venezuela: Efficacy of field Vaccination. J Clin Microbiol. 2012;50:1204-8.

14. Czegledi A, Herczeg J, Hadjiev G, Doumanova L, Wehmann E, Lomniczi B. The occurrence of five major Newcastle disease virus genotypes (II, IV, V, VI 
and VIIb) in Bulgaria between 1959 and 1996. Epidemiology Infect. 2002;129:679-88.

15. Herczeg J, Pascucci S, Massi P, Luini M, Selli L, Capua I, et al. A longitudinal study of velogenic Newcastle disease virus genotypes isolated in Italy between 1960 and 2000. Avian Pathol. 2001;30:163-8.

16. Herczeg J, Wehmann E, Bragg RR, Travassos DPM, Hadjiev G, Werner O, et al. Two novel genetic groups (VIIb and VIII) responsible for recent Newcastle disease outbreaks in Southern Africa, one (VIlb) of which reached Southern Europe. Arch Virol. 1999;144:2087-99.

17. Lee YJ, Sung HW, Choi JG, Kim JH, Song CS. Molecular epidemiology of Newcastle disease viruses isolated in South Korea using sequencing of the fusion protein cleavage site region and phylogenetic relationships. Avian Pathol. 2004:33:482-91.

18. Lien YY, Lee JW, Su HY, Tsai HJ, Tsai MC, Hsieh CY, et al. Phylogenetic characterization of Newcastle disease viruses isolated in Taiwan during 2003-3006. Vet Microbiol. 2007;123:194-202.

19. Liu HZ, Wang Y, Wu D, Zheng C, Sun D, Bi Y, et al. Molecular epidemiological analysis of Newcastle disease virus isolated in China in 2005. J Virol Methods. 2007;140:206-11.

20. Tan SW, Aini I, Omar AR. Sequence and phylogenetic analysis of Newcastle disease virus genotypes isolated in Malaysia between 2004 and 2005. Arch Virol. 2010;155:63-70.

21. Tsai HJ, Chang KH, Tseng CH, Frost KM, Manvell RJ, Alexander DJ. Antigenic and genotypical characterization of Newcastle disease viruses isolated in Taiwan between 1969 and 1996. Vet Microbiol. 2004;104:19-30.

22. Ballagi-Pordany A, Wehmann E, Herczeg J, Belak S, Lomniczi B. Identification and grouping of Newcastle disease virus strains by restriction site analysis of a region from the $F$ gene. Arch Virol. 1996;141:243-61.

23. Yang CY, Shieh HK, Lin YL, Chang PC. Newcastle disease virus isolated from recent outbreaks in Taiwan phylogenetically related to viruses (genotype VII) from recent outbreaks in Western Europe. Avian Dis. 1999;43:125-30.

24. Yu L, Wang Z, Jiang Y, Chang L, Kwang J. Characterization of newly emerging Newcastle disease virus isolates from the People's Republic of China and Taiwan. J Clin Microbiol. 2001;39:3512-9.

25. Tan SW, Aini I, Omar AR, Yusoff K, Bejo MH. Detection and differentiation of velogenic and lentogenic Newcastle disease viruses using SYBR Green I real-time PCR with nucleocapsid gene-specific primers. J Virol Method. 2009;160:149-56.

26. Liang R, Cao DJ, Li JQ, Chen J, Guo X, Zhuang FF, et al. Newcastle disease outbreaks in western China were caused by the genotypes VIla and VIII. Vet Microbiol. 2002;87:193-203.

27. Moscoso H, Alvarado I, Hofacre CL. Molecular analysis of Infectious Bursal Disease Virus from Bursal Tissues collected on FTA Filter paper. Avian Diseases. 2006:50:391-6.

28. Bandra A. Infectious bursal disease virus strains for vaccination and inactivated bursal tissue origin vaccines. A Lohmann Animal Health News Brief. 2009;2:1-4.

29. Witter RL. Marek's disease vaccines - past, present and future [chicken versus virus - a battle of the centuries]. Current progress on Marek's Disease Research. In: Schat KA, Morgan RM, Parcells MS, Spencer JL, editors. American Association of Avian Pathologist. Kennett Square. 2001.

30. Witter RL. The changing landscape of Marek's disease. Avian Pathology. 1998:27:S46-53.

31. Wise MG, Suarez DL, Seal BS, Pedersen JC, Senne DA, King DJ, et al. Development of a real time reverse transcriptase PCR for detection of Newcastle disease virus RNA in clinical samples. J Clin Microbiol. 2004:42:329-38.

\section{Submit your next manuscript to BioMed Central and take full advantage of:}

- Convenient online submission

- Thorough peer review

- No space constraints or color figure charges

- Immediate publication on acceptance

- Inclusion in PubMed, CAS, Scopus and Google Scholar

- Research which is freely available for redistribution

Submit your manuscript at www.biomedcentral.com/submit 